\title{
Study on Knowledge Integration Model for Parametric Design
}

\author{
Xiaoyang Liu ${ }^{1, a^{*}}$, Enfu Liu ${ }^{1, b}$, Zhenyu Liu ${ }^{1, c}$, Jiangyan Jin ${ }^{1, d}$ \\ ${ }^{1}$ College of Mechanical and Electronic Engineering Hebei University of Science and Technology \\ Shijiazhuang, Hebei Province, China 050023

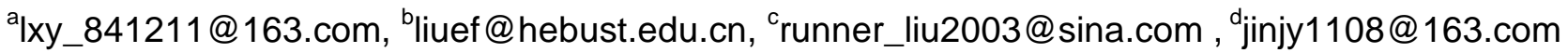

Keywords: Parametric Design, Polychromatic Sets, PS Hierarchical Structure Model, Design Knowledge Integration, Integrated Design Information Model.

Abstract. In order to improve parametric design process efficiency, design product is layer-by-layer decomposed into design unit according to the functional, and the design unit is looked as the carrier of knowledge and the object of parameter driving. In order to describe the product structure and integrate design knowledge, PS hierarchical structure model and integrated design information model are established. Based on the product information model, put forward the product parametric design steps. In order to be clear, an example of double eccentric butterfly valve parametric design is provided.

\section{Introduction}

Parametric design mainly use a set of parameters to constrain the size relations, and through driving design feature to obtain modification design results ${ }^{[1,2]}$. To ensure rapid and intelligent parametric design process, the relationships are needed between each design feature. At the same time, the key parameters are also needed to provide for parameter design process.

The parametric driving carrier is divided for design produce, which can realize the connection between product design and design knowledge to complete parametric design. In [3], the feature is as the carrier of design knowledge, which can establish association between the design process and relevant design knowledge. In [4], the geometry of steam turbine generator rotor body is analyzed, and design knowledge carrier combines both the technology of feature modeling and parametric design technology. In [5], the knowledge carrier is the rectangular cross section which is simplified by the bearing member complex surface shape.

On the basis of the above theory and technology research, the purpose is to improve the efficiency of design work in the system construction and the process of product parametric design. Aiming at complicated product parametric design problem, each design problem is divided into design unit which is direct parameter drove according to the design and assembly relationship.

The polychromatic sets theory ${ }^{[6,7]}$ which is developed by a famous Russian aircraft design \& manufacture expert Professor V.V. Pavlov is a new kind of system mathematical modeling theory in aviation industry. The mathematical modeling of the polychromatic sets can describe the relationship between the technical concepts of complicated mechanical system.

The method of using polychromatic sets theory to solve the problem of parametric design, has unified form, simple mathematical programming such outstanding advantages.

\section{DESIGN UNIT AND ITS INFORMATION EXPRESSION}

Design unit is design link which is constituted of a certain assembly, design association and the independent parameter driven. Each design unit may be a single part, component or typical structure components, or it can be a design structure component or with design relationship parts assembly of a complex parts. According to the interaction of design conditions and design constraints, design product is the layer to decompose into design unit to seek mapping process between physical structure and functional requirements according to the functional. Based on Polychromatic Sets, the product 
design information model and assembly constraint model are established, and all information is stored in Boolean matrix in the form of " 0,1 " encoding as shown in formula (1) and formula (2).

In formula (1), $[A \times F(A)]$ describes the relationship between set $A$ and uniform color $F(A)$, and set $A$ and color $F(A)$ respectively represent design units and its properties. If $F_{j} \in F\left(a_{i}\right)$, and $c_{i(j)}=1$, then $c_{i(j)}=0$.

$$
\left\|c_{i(j)}\right\|_{A, F(A)}=[A \times F(A)]=\left[\begin{array}{ccccc}
F_{1} & \mathrm{~L} & F_{j} & \mathrm{~L} & F_{m} \\
c_{11} & \mathrm{~L} & c_{1 j} & \mathrm{~L} & c_{1 m} \\
\mathrm{M} & \mathrm{M} & \mathrm{M} & \mathrm{M} & \mathrm{M} \\
c_{i 1} & \mathrm{~L} & c_{i j} & \mathrm{~L} & c_{i m} \\
\mathrm{M} & \mathrm{M} & \mathrm{M} & \mathrm{M} & \mathrm{M} \\
c_{n 1} & \mathrm{~L} & c_{n j} & \mathrm{~L} & c_{n m}
\end{array}\right] \mathrm{M}
$$

In formula (2), $F_{1}\left(a_{i}, a_{j}\right), F_{2}\left(a_{i}, a_{j}\right), F_{3}\left(a_{i}, a_{j}\right), F_{4}\left(a_{i}, a_{j}\right)$ and $F_{5}\left(a_{i}, a_{j}\right)$ respectively represent Arc-Link, AND-Split, AND-Join, OR-Split and OR-Join, and are abbreviated as $F_{1}, F_{2}, F_{3}, F_{4}, F_{5} .(A \times A)$ represent the relationship between design units.

$$
\left\|c_{i(j)}\right\|_{A, F(A)}=[(A \times A) \times F(A)]=\left[\begin{array}{ccccc}
F_{1} & F_{2} & F_{3} & F_{4} & F_{5} \\
c_{11} & c_{12} & c_{13} & c_{14} & c_{15} \\
\mathrm{M} & \mathrm{M} & \mathrm{M} & \mathrm{M} & \mathrm{M} \\
c_{i 1} & c_{i 2} & c_{i 3} & c_{14} & c_{i 5} \\
\mathrm{M} & \mathrm{M} & \mathrm{M} & \mathrm{M} & \mathrm{M} \\
c_{n 1} & c_{n 2} & c_{n 3} & c_{n 4} & c_{n 5}
\end{array}\right] \begin{gathered}
\left(a_{1}, a_{2}\right) \\
\mathrm{M} \\
\left(a_{i}, a_{j}\right) \\
\mathrm{M} \\
\left(a_{m}, a_{n}\right)
\end{gathered}
$$

\section{ESTABLISHING PRODUCT INFORMATION MODEL}

\section{Establishing PS hierarchical structure model}

In order to describe the structure of the product information, the traditional hierarchical structure was improved and expansion, and the PS hierarchical structure model is established, and node color is added. The node and its color are expressed as ordered pairs: $\left\langle F\left(A\left(k, i_{k}, j_{k-1}\right), A\left(k, i_{k}, j_{k-1}\right)\right)\right\rangle($ except of the bottom). $A\left(k, i_{k}, j_{k-1}\right)$ expresses the $k$ layer, and the $i_{k}$ node, and its parent node is the $j_{k-1}$ node of the $k$-1 layer. $F\left(A\left(k, i_{k}, j_{k-1}\right)\right)$ expresses the color of the corresponding node $A\left(k, i_{k}, j_{k-1}\right)$.

Take double eccentric butterfly valve (as shown in Fig.2) as an example, according to the design and assembly relationship, design object is divided into a number of design units which are direct parameter drove. Its structure information is described as shown in Fig.1.

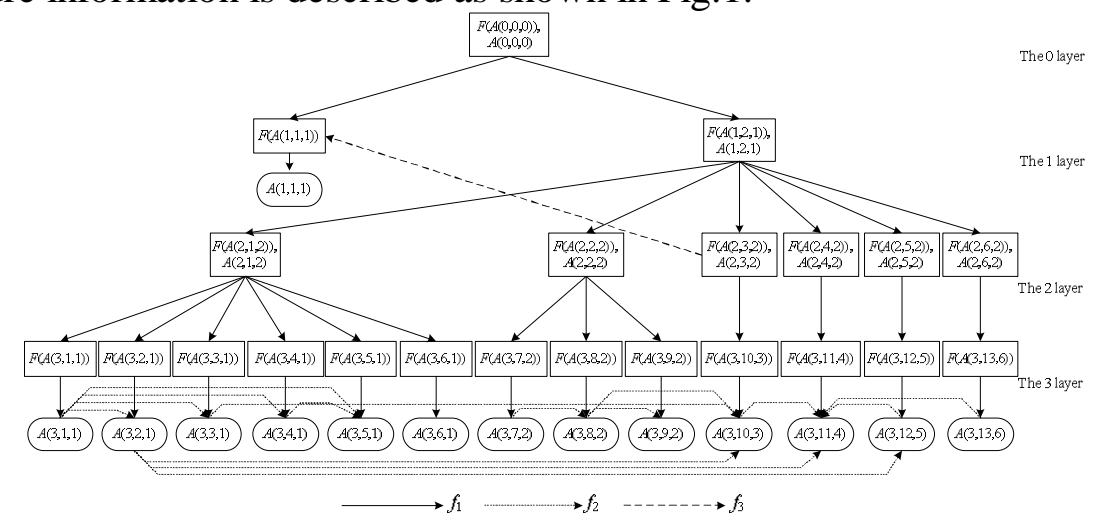

Fig. 1 The PS hierarchical structure model of double eccentric butterfly valve

The 0 layer: $F(A(0,0,0), A(0,0,0))$ is the double eccentric butterfly valve.

The 1 layer: the double eccentric butterfly valve is decomposed into two sub problems according to the function. $F(A(1,1,1))$ and $F(A(1,2,1))$ respectively express driving device and the main structure(component).

The 2 layer: the main structure (component) is decomposed into sub design problems according to the function $P_{1}, P_{2}, P_{3}, P_{4}$. Function $P_{1}$ is achieved by physical structure valve body (component) 
$F(A(2,1,2))$. Opening and closing function $P_{2}$ are achieved by physical structures butterfly plate (component) $F(A(2,2,2))$ and valve stem (component) $F(A(2,3,2))$. Connection supporting function $P_{3}$ is achieved by physical structure connecting bracket $F(A(2,4,2))$. Sealing function $P_{4}$ is achieved by physical structures upper supporting filler component $F(A(2,5,2))$ and lower supporting filler component $F(A(2,6,2))$.

The 3 layer: each design problems is divided into design unit, whereby the individual color $F(A(3,1,1)), F(A(3,2,1)), F(A(3,3,1)), F(A(3,4,1)), \ldots, F(A(3,13,6))$ respectively express barrel component, upper bearing component, lower supporting component, ...,lower supporting filler component.

The design unit is divided to form set $A$. $A=(A(3,1,1), A(3,1,2), \ldots, A(3,13,6)) . A(3,1,1)$ : barrel component $a_{1}$, upper bearing component $a_{2}, \ldots$, lower supporting filler component $a_{20}$.

The product structure information model is constructed for double eccentric butterfly valve as shown in Fig. 3. Based on Polychromatic Sets Model 01coding for product structure information ( "•" said the logic value is 1$)$. If $F\left(A\left(k, i_{k}, j_{k-1}\right)\right)$ belongs to the structure, the $i$ bit of message encoding is 1 , then it is 0 .

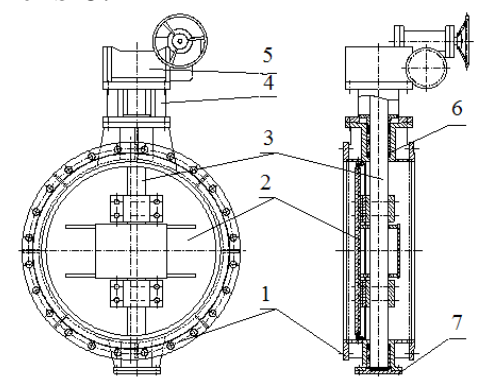

1-valve body; 2-butterfly plate; 3 -valve stem; 4-connecting bracket; 5-drive device; 6-upper supporting filler component; 7-lower supporting filler component

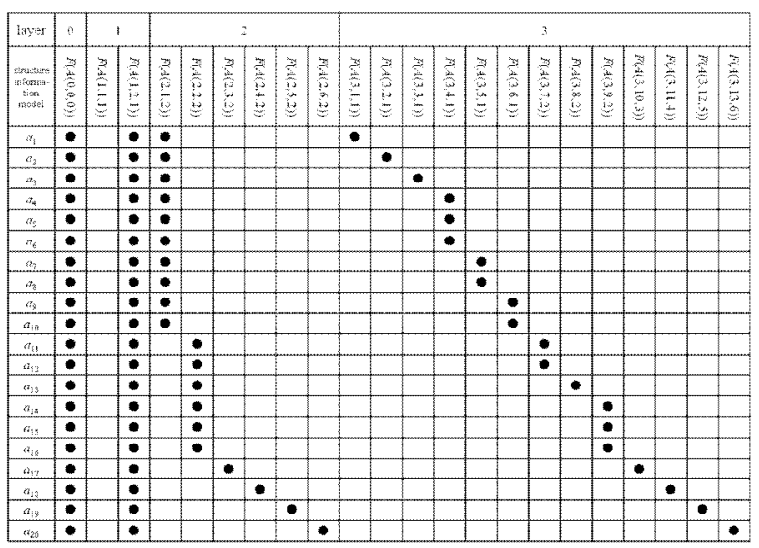

Fig. 3 The product structure information model

Fig.2 Double eccentric butterfly valve

\section{Establishing Product design knowledge model}

Uniform coloration $P_{i}$ is the overall design function of main structure. According to the relationship between the function and the design unit, the functional information matrix is established as shown in Fig. 4.

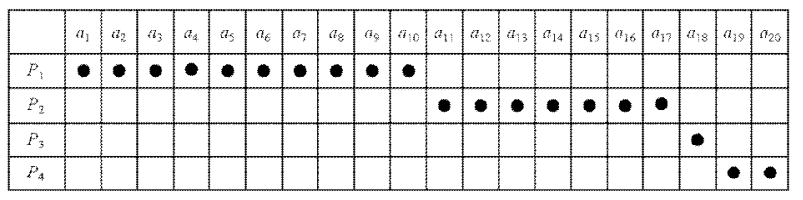

Fig.4 The functional information matrix

The key technical parameters of double eccentric butterfly valve design: $D N, \Delta D N, P N$, structure length, and wheelbase II respectively correspond to the uniform coloration $F_{1}, F_{2}, \ldots, F_{14}$, and design parameter information model is established as shown in Fig. 5.

Nodes and connection relationships of each design unit are stored in Boolean matrix as shown in Fig.6. 


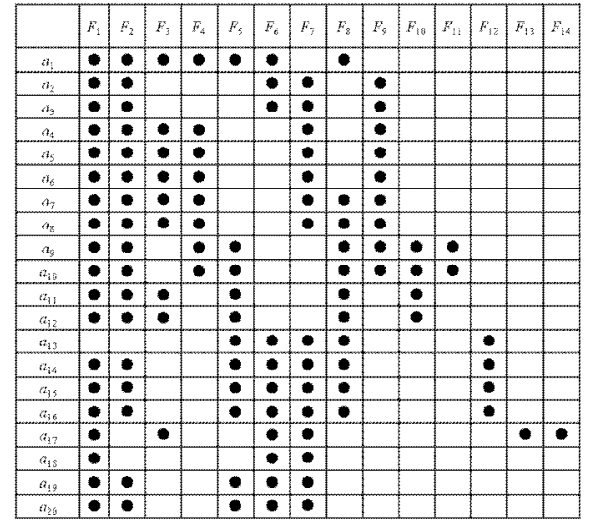

Fig.5 The key technical parameter information model

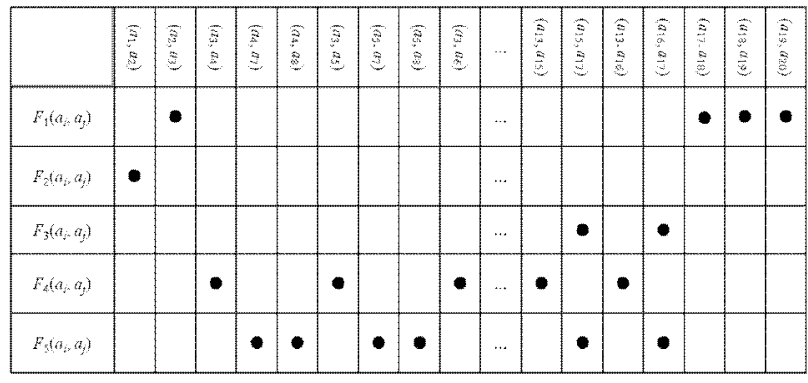

Fig.6 Nodes and connection relationship model

Design unit of double eccentric butterfly valve contains the key structure parameters: the end flange thickness, the end flange diameter, the upper supporting body diameter, the lower supporting body diameter, ..., and the connecting bracket height respectively correspond to the uniform coloration $F_{1}$, $F_{2}, \ldots, F_{24}$.

In the parametric design process, the key structure parameters affect the other design unit design. Firstly, the design unit contains are made sure by the key structure parameters, and the relationship model is established as shown in Fig.7. Then, determine the key structure parameters which restrain the other unit design, and establishing the constraint model as shown in Fig. 8.

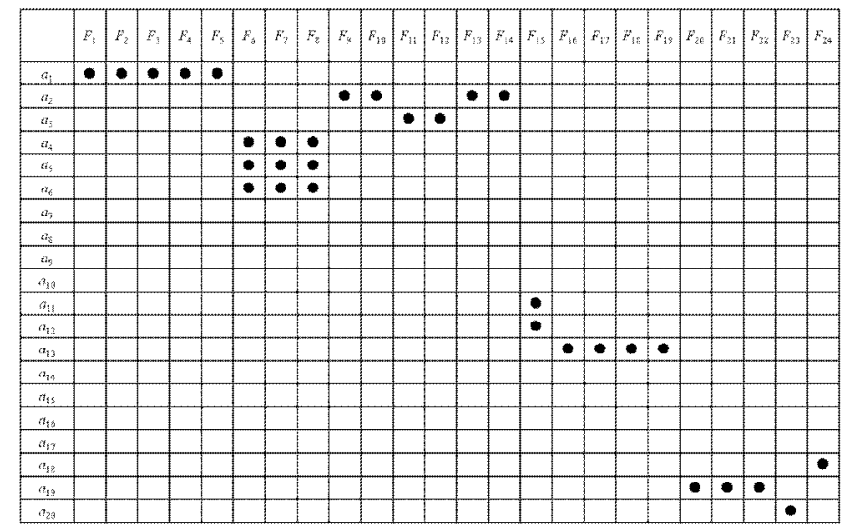

Fig. 7 The key structural parameters information model

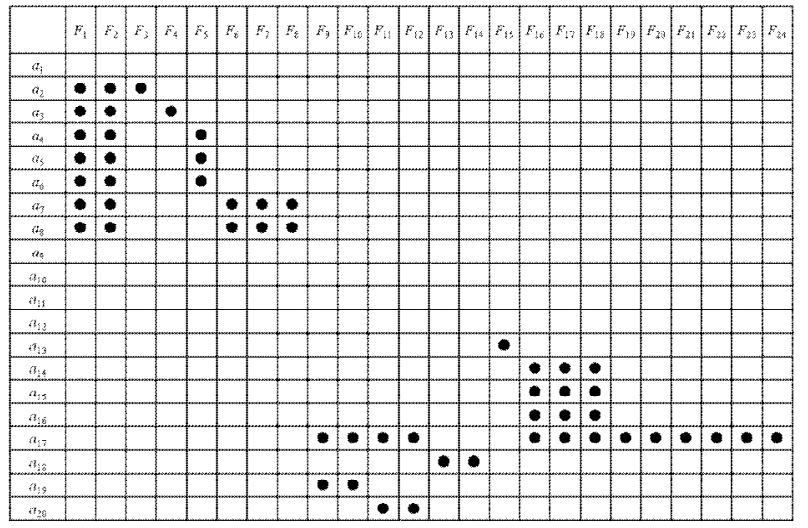

Fig. 8 The constraint model

\section{EXAMPLE}

Based on the product structure information model (as shown in Fig. 3) and design knowledge model (as shown in Fig. 4-Fig. 8), the double eccentric butterfly valve product parametric design steps are as follows:

Step1. Product design input and checking calculation for double eccentric butterfly valve as shown in Fig. 9.

Step2. Through the customer demand and calculate to obtain the key design parameters as shown in Fig. 10.

Step3. According to the functional design of double eccentric butterfly valve product, selecting the design of opening and closing function $P_{1}$. From Fig. 3 obtain the structure information coding of $a_{1}$ is 1011000001000000000000.

Step4. The parameter information coding of $a_{1}$ is 11111101000000 . Parameter design information of a1 is DN, $\triangle \mathrm{DN}, \mathrm{PN}$, the length of the structure $L$, stem diameter $d$, radial eccentricity $e_{2}$ and valve body thickness $\delta$ as shown in Fig. 11. After the barrel design is completed, and make $a_{1}=1$. 
Step5. $P_{i}=\underset{k=1}{\wedge} a_{i_{k}}=0$, and opening and closing function is not realized, and to Step2. Repeating the cycle untillo design units design is completed, opening and closing function of $P_{1}$ design is completed, and $P_{1}=1$. Then the other function design is realized.

Step6. Completing the general function $P$ design, and $P=\stackrel{4}{\wedge} P_{i=1}=1$. All design units are completed as shown in Fig. 12.

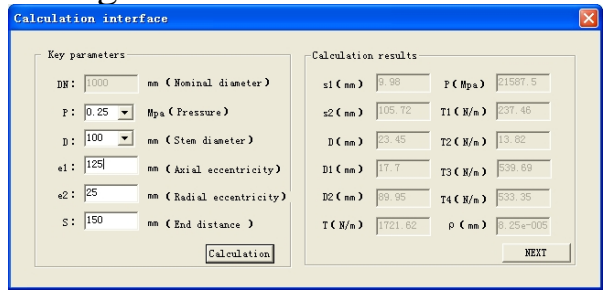

Fig.9 Design input and checking calculation

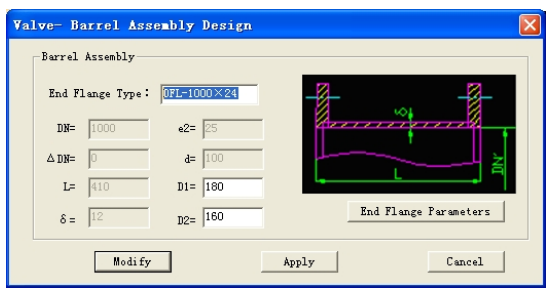

Fig.11 The barrel component design

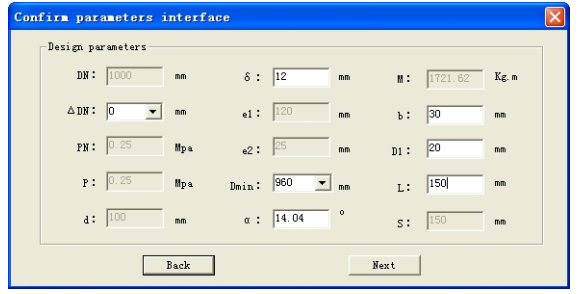

Fig.10 Key design parameters confirmation

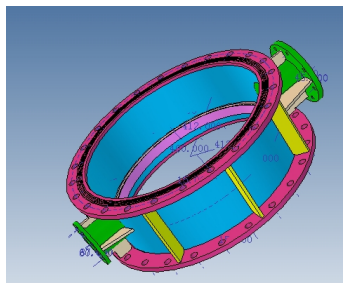

Fig.12 Double eccentric butterfly valve design

\section{Conclusions}

This paper presents a direct parameter drive design unit and the division method of design unit. Using polychromatic sets to establish the integrated knowledge model of double eccentric butterfly valve product, the association of design unit and the design knowledge of design product is completed. Through parametric drive and the assembly of design unit, the parametric design of double eccentric butterfly valve is completed.

\section{References}

[1] LV Chao, LIU Shuang, Wang Shi-ming, "Parametric integrated design for kinded jaw crusher ,"Computer Integrated Manufacturing Systems, 2013, 9(9): 2131-2140.

[2] WANG Yudong, LEI Juyang, ZHANG Lanlan, and ZHOU Qilin, "Design of Parameterized Framework in Integrated Manufacturing Environment," JOURNAL OF SHANGHAI UNIVERSITY OF ENGINEERING SCIENCE. 2015, 3(1): 65-68.

[3] WANG C B, CHEN Y J, CHU H C, “Application of ART neural network to development of technology for functional feature based reference design retrieval," Computer in Industry, 2005, 56(5): 428-441.

[4] WANG Chunhui, WANG Yanqiu, "Based on feature modeling in parametric design of turbine generator rotor," Manufacturing Information, 2011, (2): 108-109.

[5] LAN Fengchong, CHEN Jiqing, LIN Jianguo, "Reserarch on parameterized modeling and application for car," Computer Integrated Manufacturing Systems, 2005, 2(2): 183-188.

[6] Pavlov VV, "Polychromatic sets and graghs for CALS in Machine Building," Moscow, 2002.

[7] Li ZB, Xu LD, "Polychromatic sets and its application in simulating complex objects and systems," Computers \& Operations Research, 2003, 30 (6): 851-860.

[8] TANG Fengming, LI Zongbin, "A New Approach to Conceptual Design of Mechanical Products Using Polychromatic Sets," JOURNAL OF COMPUTER AIDED DESIGN \& COMPUTER GRAPHICS, 2003, 3(2): 150-155. 